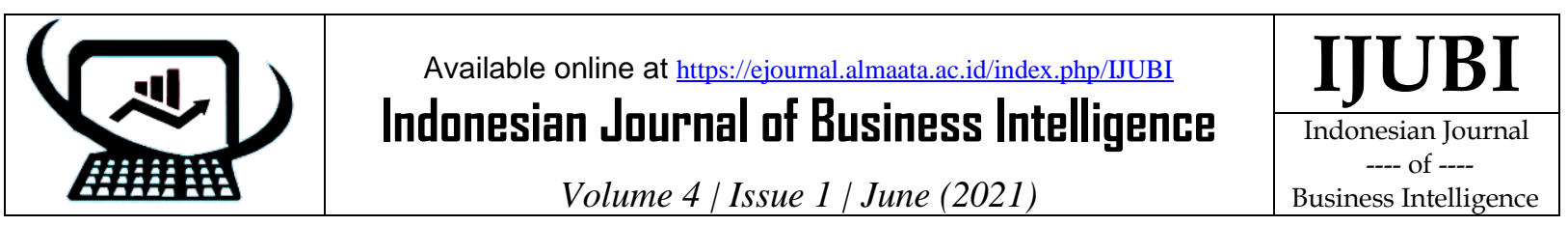

\title{
ANALISA PERFORMA ARSITEKTUR MOBILENETV1 DAN RESNET MENGGUNAKAN META-LEARNING DALAM MENDETEKSI OBJEK HEWAN KUCING
}

Faiz Octa Reynaldi ${ }^{1}$, Omar Pahlevi ${ }^{2}$, Indah Suryani ${ }^{3}$

${ }^{13}$ Teknik Informatika, Fakultas Ilmu Komputer, Sekolah Tinggi Manajemen Informatika dan Komputer Nusa Mandiri,

2Sistem Informasi, Fakultas Teknik dan Informatika, Universitas Bina Sarana Informatika.

faizoctareynaldi@gmail.com,omar.opi@bsi.ac.id, indah.ihy@nusamandiri.ac.id

${ }^{13}$ Jl. Jatiwaringin No. 02, Daerah Khusus Ibukota Jakarta 13620

${ }^{2}$ Jl. Kramat Raya No. 98, Daerah Khusus Ibukota Jakarta 10450

Keywords:

Object Detection, Transfer Learning, Cloud Computing, Few-Shot Learning, Cat

\section{Kata Kunci:}

Object Detection, Transfer Learning, Cloud Computing, Few-Shot Learning, Hewan Kucing

\begin{abstract}
Object Detection has several obstacles during the training process such as the amount of data that must be trained, takes a long time to be trained, and so on. In this study, the researchers compared the accuracy and average loss training of the MobileNetV1 SSD architecture and ResNet SSD using the Pre-Trained model with the Few-Shot Learning method using Hold-Out Cross Validation to detect Black Cat Animal Objects and White Cat Animal Objects by collecting data automatically real data from the Jakarta Vet Shop observation method and only requires a small amount of data for the training process. This research was conducted by using Cloud Computing such as Google Colab as a medium to compare the architectural accuracy of the MobileNetV1 SSD and the ResNet SSD. $97.9 \%$ for white cats while for SSD MobileNetV1 it has a mean score of $99.66666667 \%$ on black cats and $78.733 \%$ on white cats. Then SD MobileNetV1 has a greater Train Loss with an average value of 0.003923 for Black Cats and an average value of 0.0059 for White Cats when compared to ResNet's SSD with an average value of 0.030263 for Black Cats and an average value of 0.00413 for White Cats.
\end{abstract}

Object Detection memiliki beberapa kendala saat proses training seperti banyaknya data yang harus dilatih, menggunakan waktu cukup lama untuk dilatih. Pada penelitian ini, peneliti melakukan komparasi akurasi dan average loss training arsitektur SSD MobileNetV1 dan SSD ResNet menggunakan PreTrained model dengan metode Few-Shot Learning menggunakan Hold-Out Cross Validation untuk mendeteksi Objek Hewan Kucing Hitam dan Objek Hewan Kucing Putih dengan pengambilan data secara riil dari metode observasi Jakarta Vet Shop dan hanya membutuhkan sedikit data untuk dilakukannya proses training. Penelitian ini dilakukan dengan cara menggunakan Cloud Computing seperti Google Colab sebagai media untuk membandingkan akurasi arsitektur SSD MobileNetV1 dan SSD ResNet. Hasil analisa dalam penelitian ini adalah SSD ResNet memiliki akurasi yang tinggi dengan nilai rata-rata $100 \%$ pada kucing hitam dan nilai rata-rata $97.9 \%$ pada kucing putih sementara untuk SSD MobileNetV1 memiliki nilai rata-rata $99.66666667 \%$ pada kucing hitam dan $78.733 \%$ pada kucing putih. Kemudian SSD MobileNetV1 memiliki Train Loss lebih besar dengan nilai rata-rata 0.003923 pada Kucing Hitam dan nilai rata-rata 0.0059 Kucing Putih jika dibandingkan dengan SSD ResNet dengan nilai rata-rata 0.030263 pada Kucing Hitam dan nilai rata-rata 0.00413 pada Kucing Putih. 


\section{Pendahuluan}

Kebutuhan manusia akan sistem teriring dengan perkembangan pengetahuan dalam sistem komputer [1]. Dimana penggunaan teknologi informasi saat ini berkembang sangat pesat. Dengan adanya teknologi informasi diharapkan berbagai praktisi dapat terbantu dalam segala bidang. Hal ini dikarenakan teknologi informasi dapat menyimpan data hingga mengolahnya menjadi suatu hasil yang diinginkan pembuatnya [2]

Berbagai macam teknik pembelajaran dan optimasi melalui konsep machine learning dan swarm intelligence dapat memudahkan bagi pengguna di bidang teknologi kecerdasan buatan. Adapun pengertian kecerdasan buatan merupakan suatu mesin atau program yang memiliki kecerdasan didalamnya yang berguna menyelesaikan suatu pekerjaan [3]

Object detection telah menjadi topik masalah di keduanya bidang penginderaan jauh dan visi komputer. Ini umumnya didefinisikan sebagai mengidentifikasi lokasi objek target dalam gambar input serta mengenali kategori objek. Deteksi objek otomatis telah banyak digunakan di banyak aplikasi dunia nyata, seperti deteksi bahaya, pemantauan lingkungan, deteksi perubahan, perencanaan kota, dan lain-lain [4].

Lalu object detection memiliki kendala saat memasuki fase preparation, diantaranya membutuhkan banyaknya data pada sebuah dataset. Selain itu diperlukan metode seperti train dan test splitting seperti cross-validation [5]. Dengan metode tersebut, saat melakukan proses training membutuhkan waktu yang cukup lama.

Penelitian ini terkait dengan penelitian yang dilakukan oleh [6]. Dalam penelitian ini membahas mengenai arsitektur residual-network baru, Residual networks of Residual networks (RoR) untuk menggali kemampuan optimalisasi jaringan residual. RoR menggantikan optimalisasi pemetaan sisa dari pemetaan sisa untuk mengoptimalkan pemetaan residu asli. Secara khusus, RoR menambahkan koneksi pintas level-bijaksana pada jaringan residual asli untuk mempromosikan kemampuan pembelajaran jaringan sisa. Lebih penting lagi, RoR dapat diterapkan ke berbagai jenis jaringan residual (ResNets, Pre-ResNets dan WRN) dan secara signifikan meningkatkan kinerjanya. Dimana hasil eksperimen menunjukkan keefektifan dan keserbagunaan RoR, sehingga mencapai kinerja terbaik di semua struktur serupa jaringan sisa. Model RoR-3-WRN58-4 + SSD mencapai hasil mutakhir baru pada CIFAR10, CIFAR-100 dan SVHN, dengan kesalahan uji masing-masing 3,77\%, 19,73\% dan 1,59\%. Model RoR-3 juga mencapai hasil mutakhir dibandingkan dengan ResNets pada kumpulan data ImageNet.

Lalu pada penelitian yang dilakukan oleh [7], dimana membahas mengenai yang telah dilakukan, berhasil dibuat aplikasi untuk mendeteksi objek dengan menggunakan TensorFlow Object Detection API dengan memanfaatkan SSD Mobilenet V2 sebagai model pra-terlatih. Program dapat mendeteksi 5 kategori kelas objek, yaitu Camera, Handphone, Headphone, Laptop, dan Mouse. Aplikasi dapat menampilkan tingkat pengukuran akurasi masing-masing objek. Hasil pengujian yang dilakukan pada 50 test set dengan jumlah masing-masing kelas objek adalah 10 gambar. Gambar objek Camera mendapatkan rata-rata presentase sebesar 99\%, Handphone sebesar $89.1 \%$, Headphone sebesar 89.1\%, Laptop sebesar $89.1 \%$, dan Mouse sebesar 98.8\%. sehingga diperoleh rata-rata akurasi keberhasilan pendeteksian aplikasi deteksi objek adalah $93.02 \%$.

Kemudian pada penelitian [8], membahas mengenai pengolahan dataset dan training pada Machine Learning dilakukan pada server-side dan prediction dilakukan client-side menggunakan browser dengan metode pengembangan sistem Rapid Application Development dan membutuhkan banyak dataset untuk membuat suatu Pre-Trained Model MobileNet. Bahasa program yang digunakan adalah Python dan menggunakan tools seperti Jupyter Notebook, Tensorflow Keras dan Pillow. Pada hasil akhir dari penelitian ini adalah dapat memudahkan dari sisi client-user untuk melakukan membuat model klasifikasi tanpa mengunduh dependensi dan mengonversi model terlebih dahulu, 
sehingga pengguna dapat melakukan klasifikasi secara dinamis.

Pada penelitian yang dibuat oleh peneliti ini memfokuskan untuk mengefisiensi metode sebelumnya dengan metode meta-learning berbasis few shot. Adapun meta-learning adalah metode yang menggunakan optimization algorithm [9], dimana untuk melatih sebuah dataset hanya membutuhkan data yang lebih sedikit tetapi memiliki hasil yang lebih akurat [10].

Komparasi ke-dua Arsitektur antara SSD MobileNetV1 dan SSD ResNet memiliki metode training model, perhitungan dan tunning akurasi yang berbeda, perbedaan inilah yang membuat peneliti menjadi tertarik dengan mempelajari dan mengamati lebih dalam mengenai tingkat akurasi identifikasi obyek hewan kucing.

\section{Landasan Teori}

\section{A. Image Processing}

Image processing merupakan kegiatan komputer dalam hal manipulasi dan analisis suatu informasi gambar. Adapun informasi gambar yang dimaksud dengan adalah gambar visual dalam dua dimensi, dimana image processing merupakan operasi yang dapat dilakukan untuk memperbaiki, menganalisis, atau mengubah suatu gambar [11].

\section{B. Machine Learning}

Machine Learning (pembelajaran mesin) adalah salah satu dari beberapa cabang Articial Intelligence (kecerdasan buatan) dimana komputer dapat mengakses data yang sudah ada sesuai dengan perintahnya sendiri [12].

\section{Meta-Learning}

Meta-Learning juga dikenal sebagai learning how to learn. Paradigma pembelajaran potensial yang baru-baru ini muncul dapat menyerap informasi dari satu tugas dan menggeneralisasi informasi tersebut menjadi tugas yang sulit dilihat. MetaLearning pada umumnya berkerja dengan cara melibatkan penyalinan parameter jaringan pertama ke dalam parameter jaringan kedua atau ke pengoptimal [13].

\section{Python}

Python merupakan bahasa pemrograman yang memiliki keunggulan antara lain readability, efisien, multifungsi, interoperabilitas, dan memiliki dukungan komunitas yang memadai kesalahan, bug atau error lainnya [14].

\section{E. Tensorflow}

TensorFlow merupakan salah satu framework machine learning yang dapat digunakan dalam environment yang heterogeneous. Dimana dapat melakukan eksperimen model deep learning, melatih model pada dataset yang berukuran besar, dan membuatnya layak diproduksi [15].

\section{F. Google Colab}

Google Colab adalah coding environment berbasis bahasa pemrograman python. Formatnya adalah notebook hampir serupa dengan Jupyter notebook berbasis cloud computing [16].

\section{G. MobileNet}

MobileNet merupakan salah satu arsitektur convolutional neural network yang dapat digunakan untuk mengatasi permintaan sumber daya komputasi yang berlebihan [8].

\section{H. Residual Neural Network (ResNet)}

Residual Neural Network atau yang biasa dikenal dengan nama ResNet adalah satu arsitektur yang popular didalam mendeteksi suatu objek [17].

\section{Few-Shot Learning}

Few-Shot Learning (FSL) adalah jenis masalah pembelajaran mesin (ditentukan oleh experience, task dan performance), di mana experience hanya berisi sejumlah contoh dengan informasi yang diawasi untuk target task [18].

\section{J. Common Objects in Context (COCO)}

Common Objects in Context atau biasa disingkat dengan COCO adalah dataset dengan skala besar untuk deteksi objek dan segmentasi objek. Pada tahun 2015 COCO dataset telah memiliki sebanyak 165.482 train, 82.208 validation dan 81.434 test atau sebanyak $50 \%$ dalam train, 25\% dalam validation dan $25 \%$ dalam test [19].

\section{K. Domestic shord-haired cat}

Pada penelitian ini, peneliti menggunakan obyek penelitian kucing dengan ras Domestic shord-haired cat. Dimana ras ini merupakan merupakan jenis kucing berbulu pendek di luar semua ras kucing yang ada. Tipe ras kucing ini mayoritas muncul akibat kecelakaan kawin 
silang, diakibatkan perkawinan silang yang tidak disengaja dari dua ras kucing. Kemudian kucing-kucing ini kawin dengan kucing lainnya (baik kucing yang memiliki ras tertentu atau pun kucing sejenis), sehingga menghasilkan berbagai kucing yang tidak mempunyai ras tertentu [20].

\section{Metode}

\section{A. Tahapan Penelitian}

Tahap penelitian meliputi langkah implementasi dari awal. Langkah-langkahnya adalah sebagai berikut:

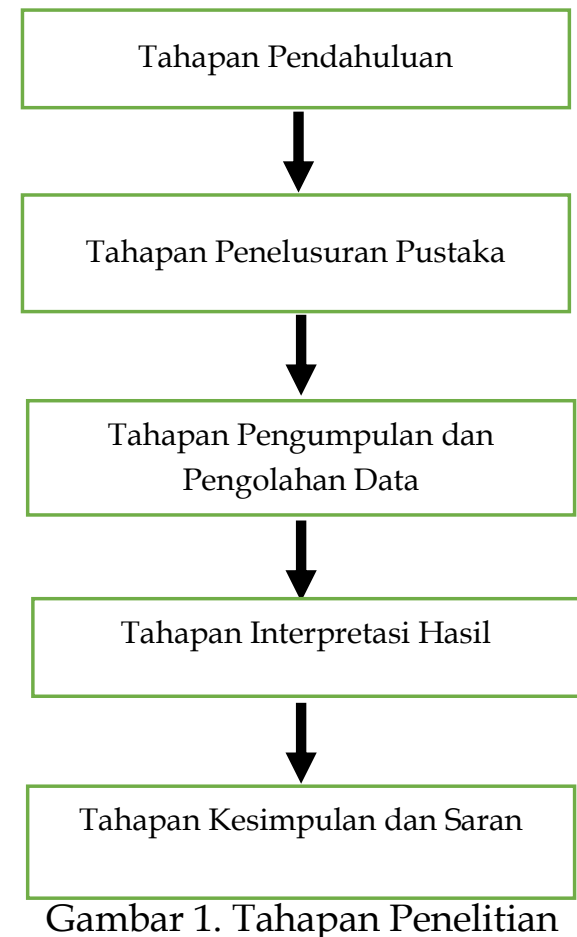

1. Tahapan Pendahuluan

Pada tahapan ini dilakukan studi literatur dan penelitian ke lapangan. Studi pustaka dilakukan untuk mempelajari secara teori dan menentukan metode yang digunakan dalam metode penelitian. Sedangkan penelitian lapangan untuk mempelajari hubungan antara metode penelitian dengan objek penelitian pada Jakarta Vet Shop Jakarta Pusat.

\section{Tahapan Penelusuran Pustaka}

Peneliti mencari bahan referensi yang berkaitan dengan penelitian sebelumnya yang berkaitan dengan tujuan penelitian, untuk mengetahui kontribusi penelitian dan melakukan penelitian kepustakaan untuk penelitian teoritis penelitian ini.

3. Tahapan Pengumpulan dan Pengolahan Data

4 "Faiz Octa Reynaldi"
Peneliti mengumpulkan data yang diperlukan sebagai bahan pemecahan masalah. Setelah itu akan dilakukan pengolahan data untuk mendapatkan interpretasi hasil penelitian

\section{Tahapan Intepretasi Hasil}

Peneliti menganalisis hasil pengolahan data berdasarkan hasil penelitian dan penelitian teoritis yang ada.

\section{Tahapan Kesimpulan dan Saran}

Pada tahap ini peneliti menarik kesimpulan atas hasil penelitian berdasarkan pengumpulan dan pengolahan data. Kesimpulan ini diambil dari hasil penelitian yang ada. Berdasarkan kesimpulan tersebut, peneliti mengajukan saran-saran yang relevan untuk proses terkait dengan tujuan penelitian agar dapat memberikan hasil yang lebih baik di masa yang akan datang.

\section{B. Metode Pengumpulan Data}

Berikut ini adalah metode pengumpulan data ada dua yaitu Penelitian Lapangan dan Penelitian Kepustakaan, berikut adalah penjelasan dari Penelitian Lapangan dan Penelitian Kepustakaan:

\section{Penelitian Lapangan}

Penelitian di lapangan merupakan kajian langsung terhadap objek penelitian, didalam penelitian ini objek yang diambil gambar secara ril untuk dilatih oleh mesin adalah hewan Kucing. Untuk memperkuat penelitian, peneliti melakukan observasi langsung pada Jakarta Vet Shop yang berada di Jalan Cempaka Putih Tengah XXX No. 5 RT. 3/ RW. 8, Jakarta Pusat.

\section{Penelitian Kepustakaan}

Penelitian Kepustakaan adalah teknik yang didasarkan pada literatur digunakan dalam metode penelitian. Selain itu, bentuk pencarian dokumen lain adalah jurnal penelitian, pertanyaan dan metodenya mirip dengan referensi penelitian.

\section{Hasil dan Pembahasan}

\section{A. Pengumpulan Data}

Pada penelitian ini menggunakan data primer dan sekunder. Dimana data primer diperoleh dari hasil observasi di Jakarta Vet Shop sebanyak lima objek hewan Kucing Putih dengan nama label kucingputih dan lima objek 
hewan Kucing Hitam dengan nama label kucinghitam untuk melakukan Training Model, sementara untuk data sekunder sendiri didapatkan peneliti dengan menggunakan PreTrained Model SSD MobileNetV1 dan SSD ResNet.

\section{B. Alur Proses Installasi Package Python}

Untuk mempermudah proses instalasi Package Python, peneliti membuat alur prosesnya sebagai berikut:

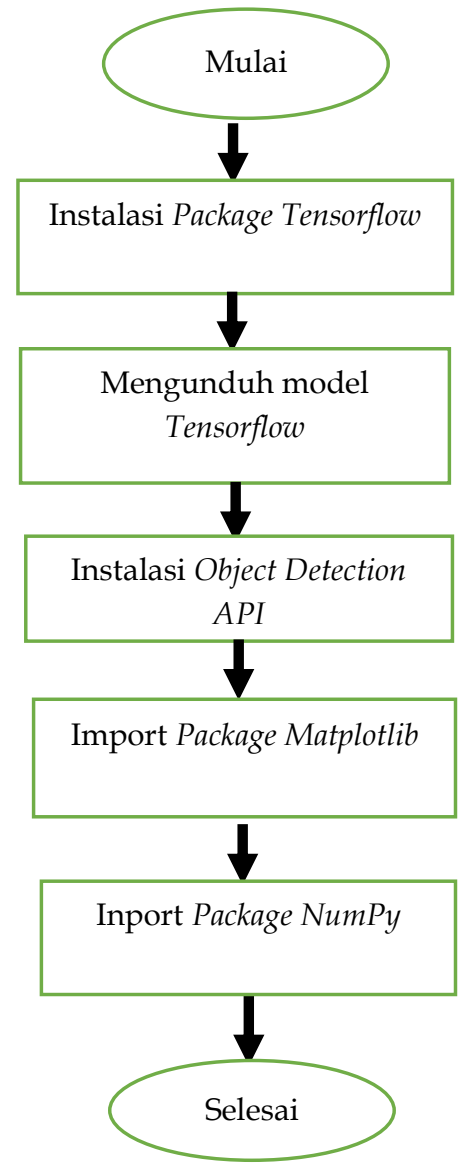

Gambar 2. Alur Proses Installasi Package Python

1. Instalasi Package Tensorflow

Langkah pertama didalam Proses Instalasi Package Python adalah dengan menginstal Package Tensorflow versi 2.2.

[ ] !pip install -U --pre tensorflow=" $2.2 .0^{\prime \prime}$

\section{Gambar 3. Instalasi Package Tensorflow}

2. Mengunduh model Tensorflow Langkah kedua adalah mengunduh model Tensorflow melalui Repository yang tersedia melalui Github.

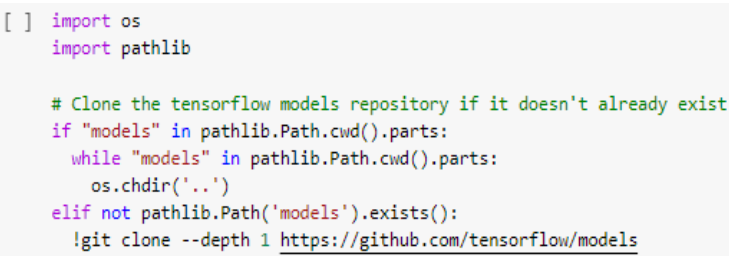

Gambar 4. Proses Unduh Model Tensorflow 3. Instalasi Object Detection API

Langkah ketiga adalah Instalasi Object Detection API, langkah ini dapat dilakukan setelah proses mengunduh model Tensorflow berhasil.

- \# Install the Object Detection API

$\%$ \%ash

cd models/research/

protoc object detection/protos $/{ }^{*}$. proto - -python out=

$c p$ object_detection/packages/tf $2 /$ setup.py .

python -m pip install.

Gambar 5. Instalasi Object Detection API

4. Import Package Matplotlib

Pada langkah keempat adalah Import Package Matplotlib, pada umumnya Matplotlib sudah terinstal secara langsung jika sudah menginstal Tensorflow terlebih dahulu.

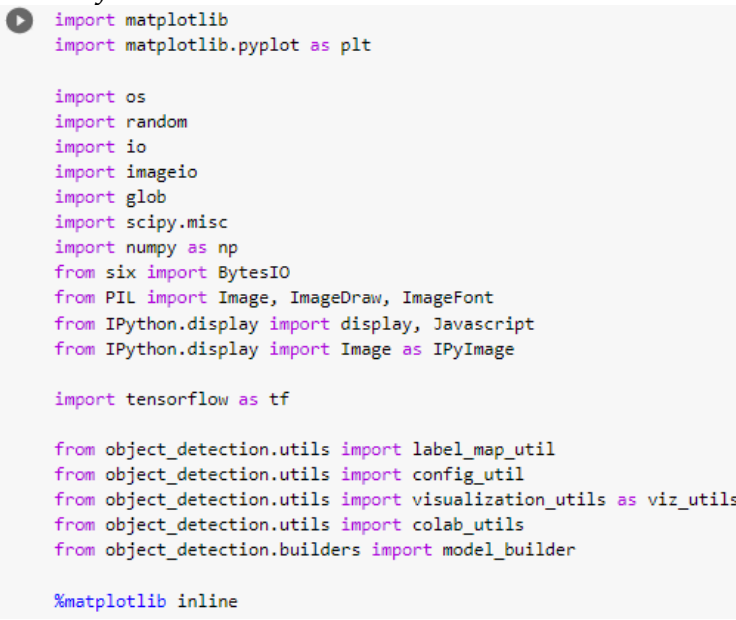

Gambar 6. Import Package Matplotlib

5. Import Package NumPy Array

Langkah terakhir dalam proses Instalasi Package Python adalah melalukan Import Package NumPy Array. Sama halnya seperti Matplotlib, NumPy umumnya sudah terinstal jika Tensorflow sudah terinstal terlebih dahulu. 


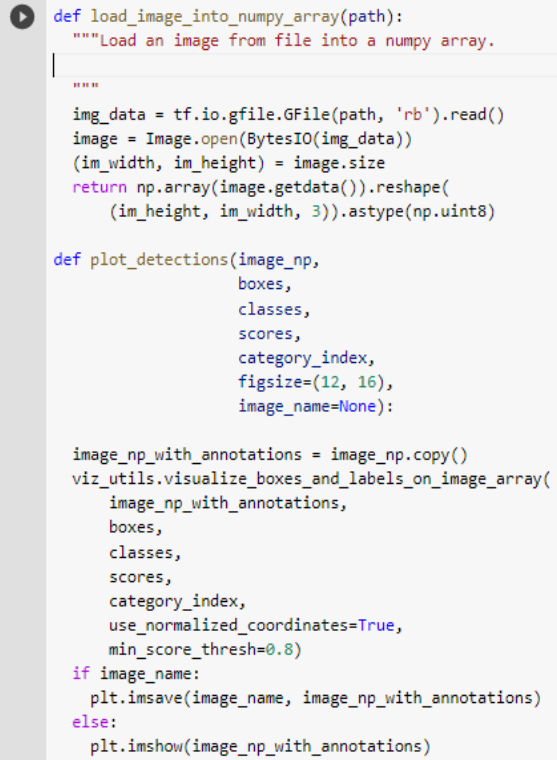

Gambar 7. Import Package NumPy Array C. Proses memberikan label pada Objek Hewan Kucing

Pada tahap ini dilakukan proses memberikan label pada Objek Hewan Kucing dengan cara membuat anotasi label sebanyak 5 (lima) gambar Hewan Kucing. Ada beberapa tahapan dalam melakukan Proses ini yaitu Load Data Image dan Anotasi Objek Hewan Kucing.

1.Load Data Image

Langkah pertama adalah dengan cara Load Data Image salin 5 (lima) Objek Hewan Kucing Putih dan Hewan Kucing Hitam kedalam direktori models/research/object_detection/test_images/kucingp utih/train/ untuk Objek Hewan Kucing Putih dan models/research/object_detection/test_images/kucing hitam/train/ untuk Objek Hewan Kucing Hitam.

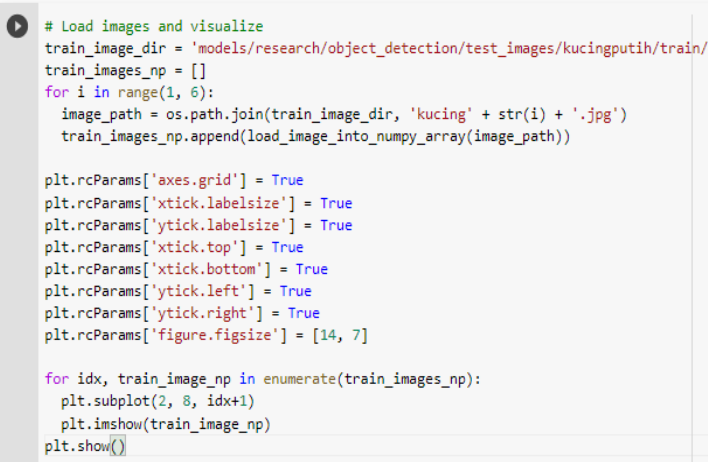

Gambar 8. Import Objek Hewan Kucing Putih

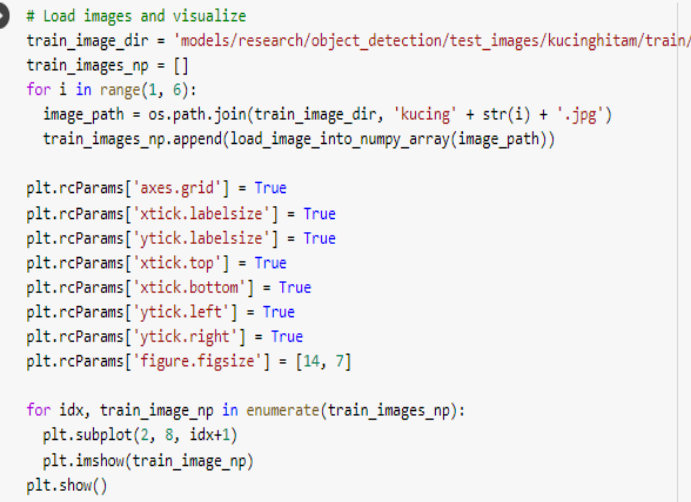

Gambar 9. Import Objek Hewan Kucing Hitam 2.Anotasi Objek Hewan Kucing

Pada langkah anotasi objek hewan Kucing yaitu memberikan label pada objek hewan Kucing Hitam dan Hewan Kucing Putih yang diambil secara riil pada Jakarta Vet Shop menggunakan bounding box dengan cara menjalankan perintah pada bahasa pemrograman python lalu berikan label menggunakan bounding box pada objek hewan Kucing Hitam dan objek hewan Kucing Putih.

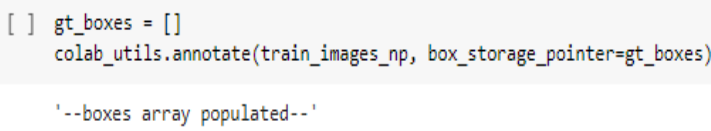

Gambar 10. Menjalankan Perintah Memberikan Label

Berikut ini tampilan memberikan label pada kucinghitam dan label kucingputih.

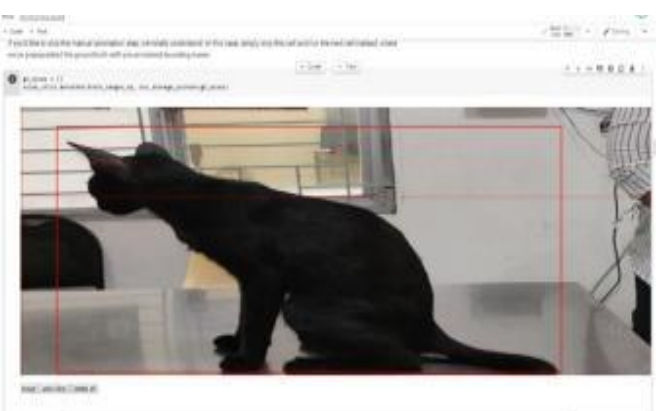

Gambar 11. Memberikan Label kucinghitam

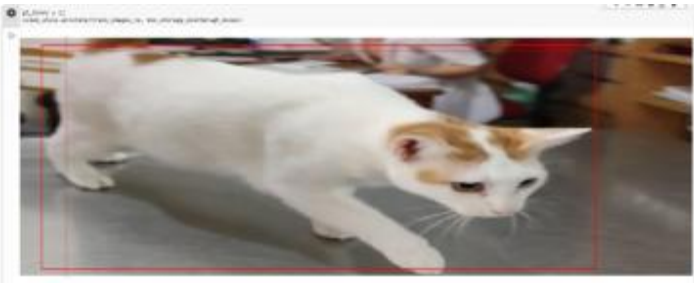

Gambar 12. Memberikan Label kucingputih 


\section{Training Model}

Training model pada Arsitektur SSD MobileNetV1 dengan menggunakan kedua objek Hewan Kucing. Training tahap pertama adalah dengan melakukan sample pada objek hewan Kucing Hitam, pada batch 100 mendapatkan total Loss sebesar 0.095, pada batch 300 mendapatkan total Loss sebesar 0.0016 dan 0.00067 pada batch 500 .

Sedangkan training model pada Arsitektur SSD ResNet dengan menggunakan kedua objek hewan Kucing. Training tahap pertama adalah dengan melakukan sample pada objek hewan Kucing Hitam, pada batch 100 mendapatkan total Loss sebesar 0.0054, pada batch 300 mendapatkan total Loss sebesar 0.00039 dan 0.085 pada batch 500 .

\section{E. Menguji Model}

Pada tahap berikutnya adalah menguji model, tahapan ini adalah menguji tingkat akurasi dari Objek Hewan Kucing yang sudah di Training Model sebelumnya. Untuk menguji tingkat akurasi peneliti menggunakan lima gambar kucingputih dan lima gambar kucinghitam untuk dilakukan pengujian model.

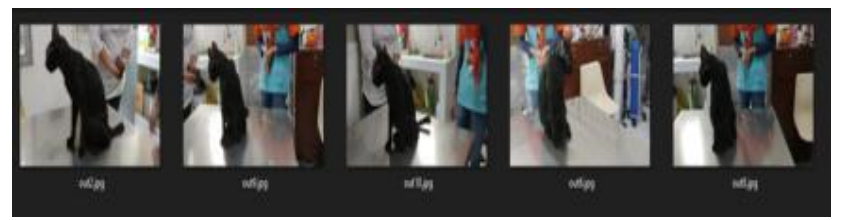

Gambar 5. Pengujian Gambar kucinghitam

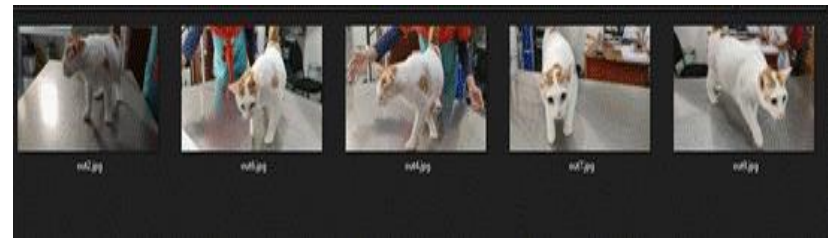

Gambar 6. Pengujian Gambar kucingputih

Berikut adalah pengujian menggunakan gambar kucinghitam dan kucingputih sebanyak 100, 300 dan 500 batch menggunakan SSD MobileNetV1.

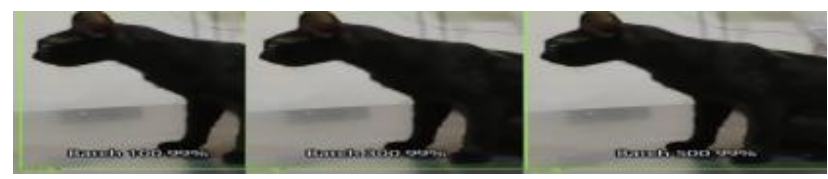

Gambar 7. Akurasi Batch 100, 300 dan 500 kucinghitam menggunakan SSD MobileNetV1

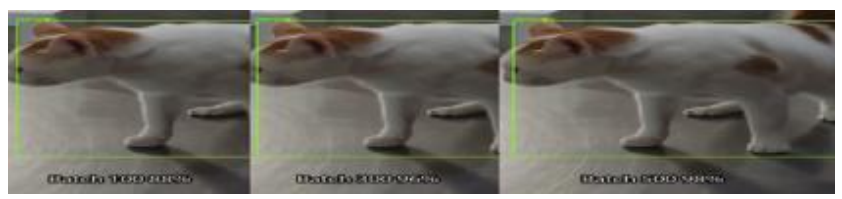

Gambar 8. Akurasi Batch 100, 300 dan 500 kucingputih menggunakan SSD MobileNetV1

Berikut adalah pengujian menggunakan kucinghitam dan kucingputih sebanyak 100, 300 dan 500 batch menggunakan SSD ResNet.

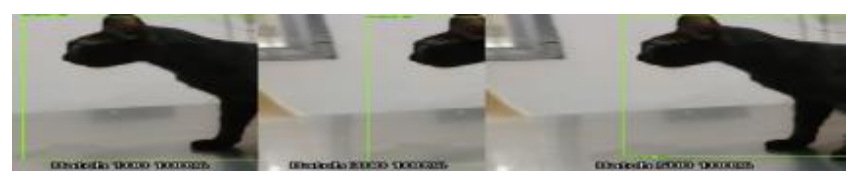

Gambar 9. Akurasi Batch 100, 300 dan 500 kucinghitam menggunakan SSD ResNet

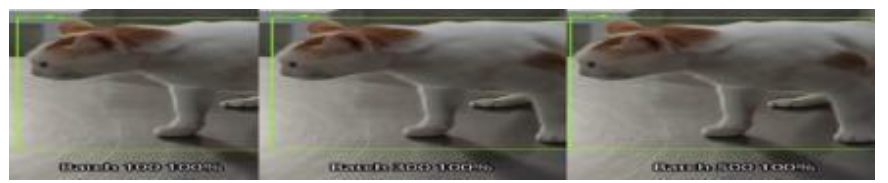

Gambar 10. Akurasi Batch 100, 300 dan 500 kucingputih menggunakan SSD ResNet

\section{F. Evaluasi model}

Evaluasi model train loss adalah mengevaluasi jumlah loss saat terjadinya proses training model dalam penelitian ini, berikut adalah Tabel Evaluasi Model Train Loss.

Tabel 1. Evaluasi Model Train Loss

\begin{tabular}{lcccccc}
\hline & \multicolumn{4}{c}{ SSD MobileNetV1 } & \multicolumn{3}{c}{ SSD ResNet } \\
& 100 & 300 & 500 & 100 & 300 & 500 \\
Jenis & batch & batch & batch & batch & batch & batch \\
\hline $\begin{array}{l}\text { Kucing } \\
\text { Hitam }\end{array}$ & 0.0095 & 0.0016 & 0.00067 & 0.0054 & 0.00039 & 0.085 \\
$\begin{array}{l}\text { Kucing } \\
\text { Putih }\end{array}$ & 0.0087 & 0.0060 & 0.0030 & 0.012 & 0.00018 & 0.00021 \\
\hline
\end{tabular}

Tabel 2. Rata-rata Train Loss kedua Arsitektur

\begin{tabular}{lcc}
\hline Label & SSD MobileNetV1 & SSD ResNet \\
\hline Jenis & Rata-rata & Rata-rata \\
Kucing Hitam & 0.003923 & 0.030263 \\
Kucing Putih & 0.0059 & 0.00413 \\
\hline
\end{tabular}

G. Evaluasi model Akurasi

SSD MobileNetV1 memiliki akurasi rata-rata 99,66666667\% dengan kesalahan tiga gambar dikarenakan memiliki dua bounding box, ResNet Akurasi rata-rata $100 \%$ dengan kesalahan tiga 
gambar dikarenakan memiliki dua bounding box dengan objek hewan Kucing Hitam.

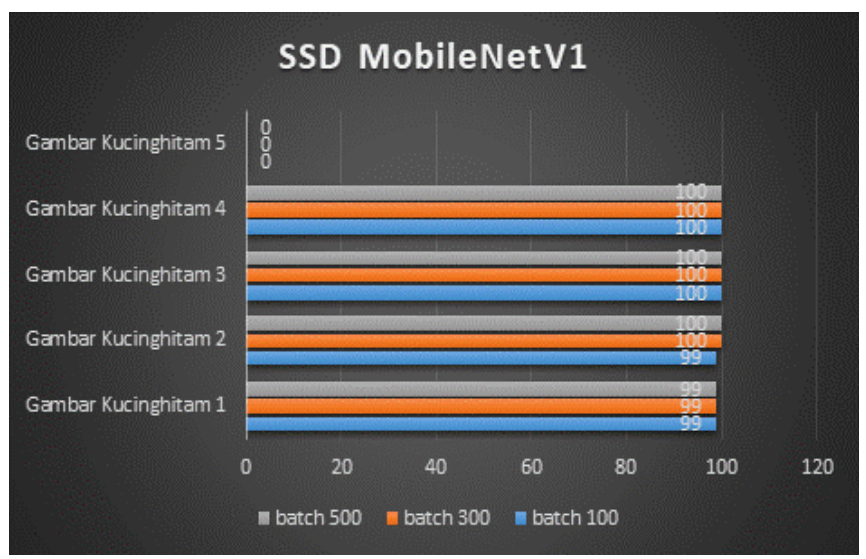

Gambar 11. Perbandingan SSD MobileNetV1 kucinghitam

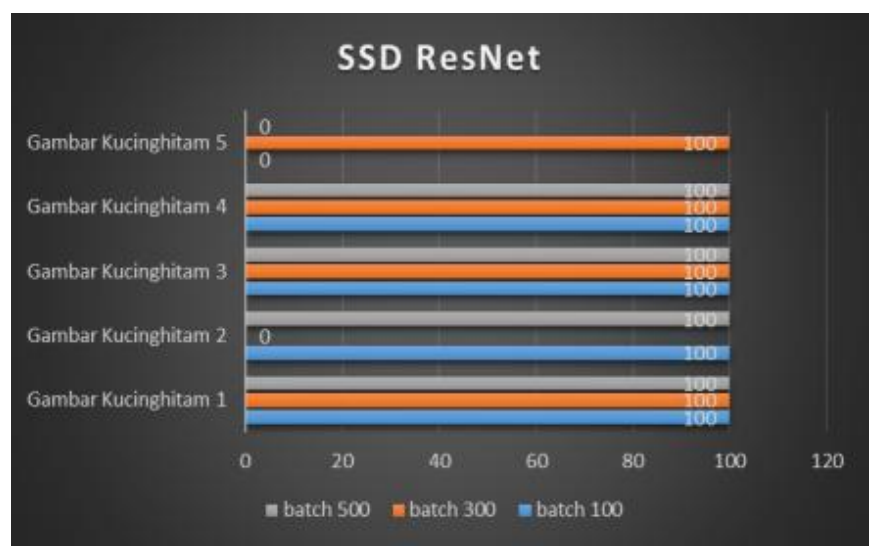

Gambar 12. Perbandingan SSD ResNet kucinghitam

MobileNetV1 akurasi rata-rata 78,733\% dengan dua kesalahan gambar dikarenakan mesin tidak dapat mendeteksi objek hewan Kucing Putih, SSD ResNet Rata-rata Akurasi 97,8\% dengan tidak ada kesalahan gambar dengan objek hewan Kucing Putih.

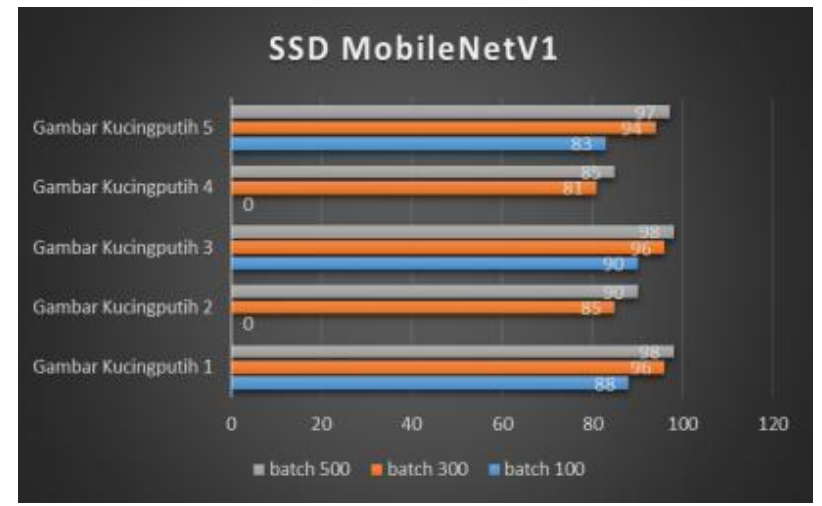

Gambar 13. Perbandingan SSD MobileNetV1 kucingputih

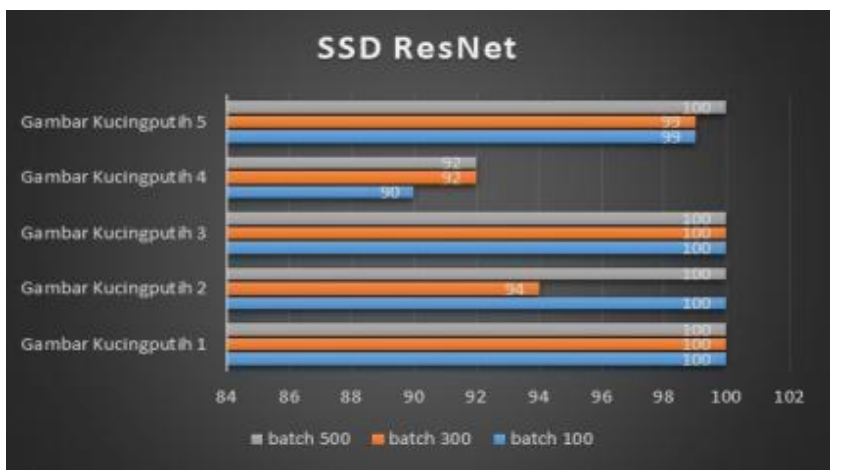

Gambar 14. Perbandingan SSD ResNet kucingputih

\section{Kesimpulan dan Saran}

Didalam penelitian ini peneliti mempunyai beberapa kesimpulan, yaitu:

1. Kualitas pengambilan gambar dan proses anotasi memberikan label berpengaruh besar terhadap hasil dari akurasi model yang akan dilatih.

2. Perbedaan jumlah training model dalam batch berpengaruh terhadap baiknya model yang akan diuji.

3. SSD MobileNetV1 memiliki train loss lebih besar dengan nilai rata-rata 0.003923 pada Kucing Hitam dan nilai rata-rata 0.0059 Kucing Putih jika dibandingkan dengan SSD ResNet dengan nilai rata-rata 0.030263 pada Kucing Hitam dan nilai rata-rata 0.00413 pada Kucing Putih.

4. SSD ResNet memiliki akurasi lebih tinggi dengan nilai rata-rata $100 \%$ pada Kucing Hitam dan $97.9 \%$ pada Kucing Putih jika dibandingkan dengan SSD MobileNetV1 dengan nilai rata-rata 99,66666667\% pada Kucing Hitam dan nilai ratarata 78,733\% pada Kucing Putih.

Didalam penelitian ini peneliti mempunyai beberapa saran, yaitu :

1. Gunakan dataset yang baik untuk menghasilkan akurasi yang baik.

2. Komparasi menggunakan Arsitektur Convolutional Neural Network lain.

\section{Referensi}

[1] E. Wijaya, "Analisis Penggunaan Algoritma Breadth First Search Dalam Konsep Artificial Intellegencia," Time, vol. II, no. 2, pp. 18-26, 2013. 
[2] A. P. Mahardika, "Sistem Pakar Mendeteksi Penyakit Dalam dengan Metode Backward Chaining Menggunakan Visual Basic 2010," pp. 2334, 2010.

[3] F. D. Wihartiko et al., "Blockchain Dan Kecerdasan Buatan Dalam Pertanian: Blockchain and Artificial Intelligence in Agriculture:," J. Teknol. Inf. dan Ilmu Komput., vol. 8, no. 1, pp. 177-188, 2021, doi: 10.25126/jtiik.202184059.

[4] J. Deng, X. Li, and Y. Fang, "Few-shot Object Detection on Remote Sensing Images," arXiv, pp. 1-12, 2020.

[5] "Wibowo - 2017 - 10 Fold-Cross Validation."

[6] K. Zhang, M. Sun, T. X. Han, X. Yuan, L. Guo, and T. Liu, "Residual Networks of Residual Networks: Multilevel Residual Networks," IEEE Trans. Circuits Syst. Video Technol., vol. 28, no. 6, pp. 13031314, 2018 ,

doi: 10.1109/TCSVT.2017.2654543.

[7] P. R. Aningtiyas, A. Sumin, and S. Wirawan, "Pembuatan Aplikasi Deteksi Objek Menggunakan TensorFlow Object Detection API dengan Memanfaatkan SSD MobileNet V2 Sebagai Model Pra Terlatih," J. Ilm. Komputasi, vol. 19, no. 3, pp. 421-430, 2020, doi: 10.32409/jikstik.19.3.68.

[8] F. E. Ramadhan, "Penerapan Image Classification Dengan Pre-Trained Model Mobilenet Dalam Client-Side Machine Learning," 2020.

[9] F. G. Mohammadi, M. H. Amini, and H. R. Arabnia, "An Introduction to Advanced Machine Learning: Meta Learning Algorithms, Applications and Promises," Adv. Intell. Syst. Comput., vol. 1123, pp. 129-144, 2020, doi: 10.1007/9783-030-34094-0_6.

[10] "Garbade - 2018 - Understanding fewshot learning in machine learning." .

[11] P. Chyan, "Penerapan Image Enhancement Algorithm Untuk Meningkatkan Kualitas Citra Tak Bergerak," Maj. Ilm. INTI, vol. 12, no. 2, pp. 278-281, 2017.

[12] "Learners - 2019 - Mengenal Machine Learning." .

[13] T. Hospedales, A. Antoniou, P. Micaelli, and A. Storkey, "Meta-Learning in Neural Networks: A Survey," pp. 1-20, 2020.

[14] E. Retnoningsih and R. Pramudita, "Mengenal Machine Learning Dengan Teknik Supervised dan Unsupervised Learning Menggunakan Python," vol. 7, no. 2, pp. 156-165, 2020.

[15] M. A. Pangestu and H. Bunyamin, "Analisis Performa dan Pengembangan Sistem Deteksi Ras Anjing pada Gambar dengan Menggunakan Pre-Trained CNN Model," J. Tek. Inform. dan Sist. Inf., vol. 4, no. 2, pp. 337-344, 2018.

[16] Reyvan, "Belajar Python dengan Google Colab,"2021.https:// www.dqlab.id/bela jar-python-dengan-google-colab.

[17] K. He, "Deep Residual Learning for Image Recognition."

[18] Y. Wang, Q. Yao, J. T. Kwok, and L. M. Ni, "Generalizing from a few examples: A survey on few-shot learning," arXiv, vol. 1, no. 1, pp. 1-34, 2019.

[19] T. Lin, C. L. Zitnick, and P. Doll, "Microsoft COCO : Common Objects in Context," pp. 1-15.

[20] "Kucing dan Jenisnya (155 ras)," 2020. http://www.kucing.biz/_kucing.php?_i $=1 \&$ jenis $=$ Domestic-Shorthaired. 